\title{
LA ÉTICA DE LA INVESTIGACIÓN EN CIENCIAS SOCIALES EN EL CONTEXTO DE LA GLOBALIZACIÓN: DE LA INVESTIGACIÓN CUANTITATIVA A LA CUALITATIVA
}

\author{
Lorenzo Agar Corbinos*
}

\begin{abstract}
Resumen: En las ciencias sociales existe un conjunto de cambios sociales y económicos, producto de la globalización, que nos lleva a reflexionar sobre la elección de las metodologías de estudio. El desafío consiste en reducir la brecha entre lo social, estudiado a través de las metodologías cuantitativas, y la socialidad, marcada por las metodologías cualitativas.

La ética surge de la cultura. Ésta nos dice sobre el inconsciente colectivo de un pueblo. La investigación debe abordar las formas apropiadas y validadas de aprehender la realidad. He aquí la evidencia más estrecha de la trilogía: cultura/ ética/investigación.

Actualmente, lo que surge desde las raíces de la vida en comunidad es una ética asociada con la socialidad y por esto es importante repensar las metodologías de investigación en las ciencias sociales.
\end{abstract}

Palabras clave: Ciencias sociales, socialidad, cultura, magia, investigación

\section{SOCIAL SCIENCES' INVESTIGATION ETHICS IN THE GLOBALISATION CONTEXT: FROM QUANTITATIVE TO QUALITATIVE INVESTIGATION}

Abstract: As a result of globalisation, a number of social and economic changes are taking place in social sciences that leads us to think about the choice of studying methodologies. The challenge consists in reducing the space between what is social, studied through quantitative methodologies, and what is "sociality", marked by qualitative methodologies. Ethics arises from culture, which tells us something about a people's unconscious collective. Investigation must find the appropriate and validated forms of apprehending reality. This is the most narrow evidence of the trilogy: culture/ ethics/investigation.

Nowadays, what spouts out of community living roots is an ethics associated with sociality, that's why it is important to think again about social sciences' investigation methodologies.

Key words: Social sciences, sociality, culture, magic, investigation

\section{A ÉTICA DA PESQUISA EM CIÊNCIAS SOCIAIS NO CONTEXTO DA GLOBALIZAÇÃO: DA PESQUISA QUANTITATIVA À QUALITATIVA}

Resumo: Nas ciências sociais existe um conjunto de mudanças sociais e econômicas, produto da globalização, que nos levam a refletir sobre a escolha das metodologias de estudo. O desfio consiste em reduzir o fosso entre ö social", estudado através das metodologias quantitativas, e "a sociabilidade", marcada pelas metodologias qualitativas.

A ética surge da cultura. Esta nos fala do inconsciente coletivo de um povo. A pesquisa deve abordar as formas apropriadas e validadas de apreender a realidade. Aqui está a evidência mais clara da trilogia: cultura, ética e pesquisa.

Atualmente o que surge a partir da vida em comunidade é uma ética associada com a sociabilidade e por isto é importante repensar as metodologias de pesquisa em ciências sociais.

Palavras chave: Ciências sociais, sociabilidade, cultura, magia, pesquisa

* Profesor del Departamento de Sociología de la Facultad de Ciencias Sociales, Universidad de Chile.

Correspondencia: agar@uchile.cl 
La preocupación formal por la ética de la investigación científica tiene su hito en la promulgación del Código de Nuremberg en 1947, surgido como reacción a los abusos cometidos por los investigadores nazis durante la Segunda Guerra Mundial. Por ser estas intervenciones de carácter biomédico, son frecuentes las posturas que asocian el tema de la ética en mayor grado a esta clase de investigación que a la relativa a las ciencias sociales. La idea central es que la investigación biomédica tiene un mayor riesgo de daño que la que se realiza en ciencias sociales. Sabemos, sin embargo, que a pesar de que la investigación social tiene en muchos casos bajo riesgo o riesgo mínimo, en otros puede implicar probabilidades de riesgo similares a las de la investigación biomédica. Un caso paradigmático es el estudio de Stanley Milgram sobre obediencia a la autoridad, realizado a fines de la década de los sesenta ${ }^{1}$. Otros ejemplos remiten a los estudios que abordan conductas estigmatizadas tales como la delincuencia, la homosexualidad, el consumo de drogas, enfermedades mentales, o los que inquieren sobre el maltrato o abuso.

Diversos son los documentos que definen los requerimientos éticos de las investigaciones, resumidos muy adecuadamente por Ezequiel Emmanuel ${ }^{2}$ : valor social y científico, validez científica, justa selección de los sujetos, positiva relación riesgo/beneficio, evaluación independiente, consentimiento informado, y respeto por la autonomía y bienestar de los sujetos. Tales requisitos, aplicables a la investigación biomédica y psicosocial, han sido consensuados internacionalmente y se ha dado una discusión extensa al respecto. Para el caso de las ciencias sociales, sin embargo, existe un conjunto de cambios sociales y económicos,

Milgram S. Obedience to Authority: An Experimental View. New York: Harper/Collins; 1983.

Emmanuel E, Wendler D, Grady C. What Makes Clinical Research Ethical? JAMA 2000; 283 (20). que podemos denominar como la "era de la globalización", que invita a reflexionar sobre la elección de las metodologías de estudio. Se trata, evidentemente, del respeto al requisito de la validez científica: utilizar una metodología que sea validada y aceptada por la comunidad científica.

La paradoja que intentaremos ilustrar en esta reflexión dice relación, por un lado, con el avance de los métodos de observación social y, por otro, con la escasa participación de la población en cuanto conjunto de sujetos autónomos y activos de estas investigaciones. En rigor, se podría pensar que, en la medida que aumenta la conciencia de la importancia de la participación de los sujetos, junto con el mejoramiento de las técnicas de observación, debería ocurrir que las personas que son objeto de la investigación tendrían mucho más que decir sobre la forma, para el caso de encuestas sociales por ejemplo, de plantear las preguntas, el tipo de preguntas y de qué manera los resultados podrían ser útiles para los fines originalmente perseguidos.

Veamos someramente algunos de los cambios sociales que están en la base de lo que estamos señalando:

La mayor y más activa participación de las mujeres en la esfera de lo público ha traído consigo cambios en las relaciones entre los sexos y la consideración de género. Las interrelaciones, por un lado, del sexo, definido por un hecho biológico y, por otro, los principios arquetípicos de lo masculino y femenino presentes en todo ser humano, están produciendo un cambio sustantivo en la apreciación de género, cuya definición es cultural. Es decir, están produciendo un cambio en cómo la sociedad, los grupos o microgrupos sociales perciben y reaccionan frente a los cambios en los múltiples roles del hombre y la mujer, tanto entre ellos como de ellos frente a la sociedad. En este sentido es 
necesario preguntarse de qué forma las encuestas o entrevistas a que son sometidos hombres y mujeres en una investigación social dan cuenta de este nuevo hecho social. ¿Es necesario considerarlos? ¿Deben aplicarse métodos diferenciados? ¿Deben recogerse estas diferencias en los resultados? ¿Cómo se puede objetivar esta observación?

Estas son sólo algunas preguntas que, entre muchas otras, ya deberíamos hacernos respecto de los profundos cambios culturales sobre la consideración de género, y que están ocurriendo sobre la base de las nuevas relaciones entre la definición biológica del sexo y los principios arquetípicos. ¿Dionisio o Apolo? La nueva mujer apolínea al frente de los asuntos públicos, versus el nuevo hombre dionisíaco que se encarga de los asuntos privados o domésticos.

Visto de otra manera, se trata de reducir la distancia entre lo social, estudiado a través de las metodologías cuantitativas, duras, apolíneas, masculinas, y la socialidad, marcada por las metodologías cualitativas, blandas, dionisíacas, femeninas. Este acercamiento es, sin duda, uno de los signos de los tiempos de la globalización o posmodernidad como otros quieren llamarlos. También son un signo, por supuesto, las transformaciones que, en forma de sinastría ${ }^{3}$, aparecen en las ciencias sociales junto con el término de la guerra fría y el derrumbe de la llamada verificación de hipótesis sociales con las teorías sociales respectivas y las recetas para un mundo mejor, cuyo precio experimental debieron sufrir las sociedades totalitarias de distinto signo ideológico durante la segunda mitad del siglo XX.

Visto de otra manera, es la tensión entre lo social, que se intenta evaluar a través de indicadores cuantificables, y la socialidad, ese es-

Por ahora no discutiremos la causalidad entre estos fenómenos, pero el debate queda abierto. tar con él o los otros sin un objetivo funcional, con una cierta indolencia respecto de los fines y no adoptando una forma medible sencilla, sino a través de la apreciación subjetiva de la propia forma y calidad de vida.

La ética de la investigación incluye el respeto por la cultura y el reconocimiento de las formas básicas de la organización social. Esto, asociado ya no tanto ahora con la estructura social, con la metodología llamada dura, sino con la mirada blanda, asociada con la socialidad. Y, en este caso, el respeto ético debe centrarse mucho más en la formulación de un problema de investigación con sentido cultural, que debiera ser resuelto con la participación de los actores, mucho más conscientes y vigilantes.

El impresionante aumento de la esperanza de vida, veinte años en los últimos cincuenta años, asociado con la actual baja fecundidad, ha traído consigo un creciente envejecimiento en la estructura demográfica. Así como antes hacíamos mención a los cambios culturales sobre el género, aquí también existen transformaciones relativas a la consideración cultural de la edad biológica. El sexo es al concepto de género como la edad al concepto de cronocultura. Ahora bien, vale la pena reflexionar acerca de cómo los cambios en este concepto también afectan y pueden ser afectados por la investigación social. ¿Cómo la investigación blanda y dura deben aliarse para mejor enfrentar estos cambios que están produciendo, a su vez, transformaciones en las formas de relacionarse y en los roles familiares, la diversidad del consumo y la educación permanente, entre otros?

La ética trata de las costumbres y modos de ser, con las obligaciones respectivas, del ser humano. Se entiende que éste pone en funcionamiento su ética en el contexto de su cultura y en la relación con otras personas. La investigación en ciencias sociales pretende comprender 
la forma en que los hombres y los grupos humanos se relacionan y, sobre esa base, dar ideas y propuestas concretas para mejorar la calidad relacional y material en la vida de las personas.

La ética surge de la cultura y, luego, la moldea. La cultura nos dice sobre el inconsciente colectivo de un pueblo. La ética es la expresión consciente de aquella manifestación cultural. La investigación debe dar cuenta, desde los puntos de vista técnico y ético, de las formas apropiadas y validadas de aprehender la realidad. He aquí la evidencia más estrecha de la trilogía: cultura/ética/investigación.

Se está pasando de la cultura paternalista hacia la cultura de la autonomía, o de la participación, que incluye, asimismo, la responsabilización de los sujetos.

La calidad de vida es una apreciación subjetiva de la forma en que vivimos y que, por definición, tiene carácter individual. Tratar de cuantificar la calidad a través de indicadores cuantitativos -por ejemplo, el Índice de Desarrollo Humano (IDH) - es una tarea nada senci1la. Se usa -y se abusa- ya que los parámetros modernos para evaluar así lo exigen. Pero sabemos muy bien que pueblos con bajos índices de desarrollo viven más felices: se siente, se sabe, se vive y eso se comprueba al compartir las emociones y apreciar cómo experimentan y disfrutan los momentos cotidianos. Son los conocidos valores vivenciales de que nos habla Víctor Frankl, entre los que cabe mencionar los de "creación" y "actitud". Frankl destaca, además, que estos valores dicen relación con la importancia que se puede prestar a la belleza de la naturaleza o del arte, y que no se debe menospreciar la plenitud de sentido que esta clase de valores puede dar a la vida humana ${ }^{4}$.

\footnotetext{
Frankl VE. Psicoanálisis y Existencialismo: de la Psicoterapia a la Logoterapia. México: Breviarios del Fondo de Cultura Económica. Cuarta reimpresión; 1990.
}

La calidad de vida podría definirse como aquella capacidad de los individuos - organizados en forma espontánea, sin objetivo estructurado y con medios surgidos de su propia imaginación-, que permite vivir momentos de gozo en compañía de otras personas. La calidad de vida se encuentra fuertemente condicionada por el medio cultural y ligada a los valores de los individuos y de los grupos sociales.

Nos encontramos en presencia de una verdadera cultura de sentimientos. La cultura no es solamente un punto de vista racional, más bien pone en juego afectos. Resulta difícil comprender un sentimiento aislado de la cultura. Ambos forman parte de un engranaje afectivo de alta complejidad en el que intervienen las creencias, valores, esperanzas y miedos de la sociedad y de los individuos. Frente al evidente regreso de lo mágico, nuestra tarea como investigadores de las relaciones sociales es aprender a reflexionar sobre lo impensable, sobre aquello que creíamos impenetrable y hacerlo desde lo no-racional ${ }^{5,6}$.

Lo que emerge desde las raíces de la vida en comunidad es la búsqueda de aquellos puntos de encuentro que digan relación con un compartir ético de la socialidad por sobre la tradicional estructura social.

La reflexión en las ciencias sociales debe tomar en consideración esta nueva realidad y reconocer que nuevas formas de relación humana están surgiendo y que será necesario utilizar nuevos esquemas de interpretación y modelos para la acción, considerando las emociones, las sensaciones y la intuición en un lugar tanto o más destacado que el tradicional pensamiento empírico.

Maffesoli M. Elogio de la razón sensible. Una visión intuitiva del mundo contemporáneo. Barcelona, Buenos Aires: Editorial Paidós; 1997.

6 Maffessoli M, Agar L. El surgimiento de lo trágico y nuevas formas de insurrección social. Acta Bioethica 2002; 8 (1): 21-6. 